\section{Factors affecting specialist psychiatry training in South Africa: Bullying during specialist psychiatric training?}

To the Editor: As many of us served as members of the Council of Psychiatrists, Colleges of Medicine of South Africa, for the triennium 2017 - 2020, we were keen to understand how workplace experiences and supervision could affect training and examination outcomes in South African (SA) centres.

We conducted a cross-sectional, descriptive study of registrar trainees in psychiatry at the University of the Witwatersrand, the University of Cape Town, the University of KwaZulu-Natal, the University of Pretoria, the University of the Free State, Stellenbosch University, the University of Limpopo, and Walter Sisulu University between 1 June and 30 November 2019. We made use of an online survey that included questions on bullying/discrimination. All questions were closed-ended.

Approval to conduct the study was obtained from the Health Research Ethics Committee at Stellenbosch University (ref. no. N18/06/063). Additionally, ethical and institutional permissions were obtained from all participating training institutions. Registrar participation was voluntary and anonymous, and informed consent was obtained from all participants.

The estimated number of psychiatry registrars in the country was 179, and we received 70 responses (39.1\% response rate). Just under half of the registrars $(n=34 ; 48.6 \%)$ reported having been bullied or harassed. Consultants $(n=21)$ were most frequently cited as the culprits, followed by patients or patients' relatives $(n=17)$, hospital management $(n=12)$, other registrars $(n=11)$, nurses $(n=9)$ and lastly university management $(n=2)$.

The most frequently experienced type of bullying was belittling/ humiliation $(n=26)$, followed by being threatened/insulted $(n=17)$, being deliberately prevented from accessing training $(n=7)$ and other forms of bullying $(n=2)$ (these were 'silent treatment' by nurses and being forced to work in an unsafe clinic).

Of the respondents who reported experiencing harassment/ bullying, more than a third $(35.3 \%)$ reported being afraid of the consequences should they report the incident, $23.5 \%$ indicated that they had reported the issue and that it had been resolved, $17.6 \%$ stated that they had reported it but that it had not yet been resolved or that they still intended to report it, $14.7 \%$ felt that reporting the incident would not make a difference, and $8.8 \%$ thought that the incident was not serious enough to report.

These findings are of considerable concern in view of the negative consequences that bullying has been shown to have on registrars' mental health ${ }^{[1,2]}$ and consequently on rates of burnout, ${ }^{[3]}$ substance abuse, ${ }^{[4]}$ satisfaction with residency ${ }^{[1]}$ and entertaining thoughts of programme non-completion. ${ }^{[2,4]}$ Bullying has also been found to negatively affect professionalism, ${ }^{[5]}$ teamwork and communication, with downstream impacts on patient morbidity ${ }^{[6]}$ and mortality. ${ }^{[7]}$

In conclusion, bullying and harassment are common experiences during psychiatry registrar training in SA and are under-reported for a variety of reasons. As supervising psychiatrists, we have an obligation to our trainees to ensure that they are treated with respect, protected and nurtured during their training.

\section{Natalie Beath, Karis Moxley}

Department of Psychiatry, Faculty of Medicine and Health Sciences, Stellenbosch University, Cape Town, South Africa

nbeath@gmail.com

\section{Ugasvaree Subramaney}

Department of Psychiatry, Faculty of Health Sciences, University of the Witwatersrand, Johannesburg, South Africa

\section{Zukiswa Zingela}

Department of Psychiatry, Faculty of Health Sciences, Walter Sisulu University, Mthatha, South Africa

\section{Bonginkosi Chiliza}

Department of Psychiatry, School of Clinical Medicine, University of KwaZulu-Natal, Durban, South Africa

\section{John Joska}

HIV Mental Health Research Unit, Department of Psychiatry and Mental Health, Faculty of Health Sciences, University of Cape Town, South Africa

\section{Carla Kotzé}

Department of Psychiatry, Faculty of Health Sciences, University of Pretoria, South Africa

\section{Soraya Seedat}

Department of Psychiatry, Faculty of Medicine and Health Sciences, Stellenbosch University, Cape Town, South Africa

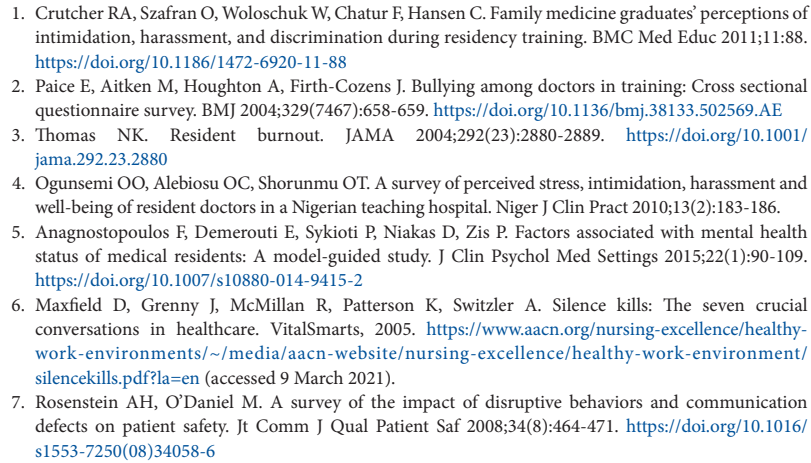
intimidation, harassment, and discrimination during residency training. BMC Med Educ 2011;11:88. https://doi. org/10.1186/1472-6920-11-88

2. Paice E, Aitken M, Houghton A, Firth-Cozens J. Bullying among doctors in training: Cross sectional questionnaire survey. BMJ 2004;329(7467):658-659. https:// doi.org/10.1136/bmj.38133.502569.AE

3. Thomas NK. Resident burnout. JAMA 2004;292(23):2880-2889. https://doi.org/10.1001 Thomas NK.
jama.292.23.2880

4. Ogunsemi OO, Alebiosu OC, Shorunmu OT. A survey of perceived stress, intimidation, harassment and well-being of resident doctors in a Nigerian teaching hospital. Niger J Clin Pract 2010;13(2):183-186.

5. Anagnostopoulos F, Demerouti E, Sykioti P, Niakas D, Zis P. Factors associated with mental health status of medical residents: A model-guided study. J Clin Psychol Med Settings 2015;22(1):90-109. https://doi.org/10.1007/s10880-014-9415-2

6. Maxfield D, Grenny J, McMillan R, Patterson K, Switzler A. Silence kills: The seven crucia conversations in healthcare. VitalSmarts, 2005. https://www.aacn.org/nursing-excellence/healthywork-environments/ /media/aacn-website/nursing-excellence/healthy-work-environment/ silencekills.pdf?la=en (accessed 9 March 2021).

7. Rosenstein $\mathrm{AH}, \mathrm{O}$ 'Daniel $\mathrm{M}$. A survey of the impact of disruptive behaviors and communication defects on patient safety. Jt Comm I Qual Patient Saf 2008:34(8):464-471. https://doi.org/10.1016/ s1553-7250(08)34058-6

S Afr Med J 2021;111(4):280. https://doi.org/10.7196/SAMJ.2021.v111i4.15518 